\title{
ANALISIS KESELAMATAN REAKTOR KARTINI BERDASAR KEJADIAN PEMICU YANG DIPOSTULASIKAN
}

\author{
Yohannes Sardjono, Eko Priyono, Syarip \\ Puslitbang Teknologi Maju-BATAN \\ Jn. Babarsari Kotak Pos 6101 ykbb, Yogyakarta 55281
}

\begin{abstract}
ABSTRAK
ANALISIS KESELAMATAN REAKTOR KARTINI BERDASAR KEJADIAN PEMICU YANG DIPOSTULASIKAN. Berdasarkan analisis kejadian pemicu yang dipostulasikan maka ada 8 kejadian yang dipostulasikan (Postulated Initiating Event) : seperti kehilangan catu daya listrik, kegagalan sistem scram, kehilangan aliran pendingin, kehilangan pendingin, kegagalan transfer cask, kejadian internal/eksternal dan kesalahan manusia. Dari 8 kejadian tersebut, hanya satu kejadian yang menyebabkan terlepasnya bahan radioaktif dari seluruh sistem bahan bakar ke lingkungan yaitu kejadian gagalnya sistem pemindah bahan bakar (transfer cask). Urutan kejadiannya adalah transfer cask jatuh di atas teras reaktor dan mengakibatkan seluruh kelongsong bahan bakar pecah lalu diikuti dengan hilangya seluruh air tangki reaktor sehingga seluruh inti hasil belah gas yang ada di celah bahan bakar lepas ke lingkungan. Analisis terlepasnya bahan radioaktif ke lingkungan menggunakan paket program dengan bahasa Turbo Pascal dan lama eksekusi 5 menit. Dari hasil analisis diperoleh bahwa dosis radiasi gamma yang diterima oleh penduduk pada saat 2 jam setelah terjadi kecelakaan pada radius 33 meter adalah 25 rem dan dosis iodin adalah 300 rem berarti proses evakuasi sangat sederhana karena tidak melibatkan penduduk di sekitar kawasan P3TM.
\end{abstract}

\section{ABSTRACT}

THE SAFETY ANALYSIS OF KARTINI RESEARCH REACTOR BASED ON POSTULATED INITIATING EVENT FAILURE OF TRANSFER CASK. According to the postulated initiating event, there are eight event i.e.; loss of electric power supplies, failure of scram system, loss of flow, loss of coolant, failure of transfer cask equipment, internal and external events and human error. From that postulated initiating events only one which potential consequences of the fission product released from their system. This system is failure of transfer cask equipment. The event sequences are: failure transfer cask when being use at the above of reactor core, the total of fuel cladding ruptured, the total of primary water coolant loosed, the total of gases fission product released to the reactor hall and environmental. The analysis was carried out by computer code turbo Pascal and 5 minutes executed. From the result can be concluded that the total gamma dose and lodine dose after 2 hours accident are 25 rem and 300 rem respectively for 33 meters distance from reactor core. According to the above result, the evacuation during accidents is easiest due to that distance are not involve the public living area.

\section{PENDAHULUAN}

Qerdasarkan International Atomic Energy Agency (IAEA) Safety Series No. 35-G1-1994 dan Keputusan Kepala Badan Pengawas Tenaga Nuklir (BAPETEN) No. 01-P/Ka-BAPETEN/VI-99 tentang Pedoman Penentuan Tapak Reaktor Nuklir maka setiap menilai/memilih tapak harus dibuat asumsi mengenai terlepasnya zat radioaktif hasil pembelahan dari teras reaktor pada kondisi kecelakaan. Pada asumsi tersebut harus dipertimbangkan mengenai laju kebocoran zat radioaktif dari containment dan keadaan meteorologi seperti kecepatan dan tingkat turbulensi angin di sekitarnya. Asumsi tersebut diperlukan untuk menganalisis dosis radiasi total yang diterima penduduk setelah 2 jam kecelakaan tidak melebihi 25 rem dan dosis iodin tidak melebihi 300 rem.

Untuk menentukan metode dan pendekatan yang digunakan dalam analisis keselamatan reaktor Kartini untuk operasi $100 \mathrm{~kW}$, berdasarkan analisis kejadian awal maka dipertimbangkan 1 macam kejadian yang mengakibatkan terjadinya lepasan zat radioaktif dari sistem reaktor. Kejadian tersebut adalah kegagalan transfer cask. Sedangkan analisis keselamatan reaktor jika terjadi kehilangan seluruh air pendingin primer, kegagalan sistem scram, kehilangan catu daya listrik, kehilangan aliran pendingin, dan kejadian-kejadian khusus internaleksternal seperti gempa bumi, banjir dan tanah longsor serta kesalahan operator (human error) tidak dilakukan analisis karena sesuai dengan analisis kejadian awal hal-hal tersebut tidak akan menimbulkan konsekuensi paparan radiasi dan terlepasnya zat radioaktif ke lingkungan. ${ }^{[1]}$ 
Kriteria penerimaan yang digunakan dalam analisis keselamatan ini adalah SK. Ka. BAPETEN No. 01-P/ Ka-BAPETEN/VI-1999. Jari-jari daerah eksklusi harus dipilih sedemikian hingga seseorang yang berada pada batas luar daerah eksklusi tidak akan menerima dosis gamma total lebih dari 25 rem untuk seluruh tubuh atau dosis karena radiasi beta dari iodin untuk kelenjar gondok tidak lebih dari 300 rem selama 2 jam sesudah kecelakaan terparah terjadi. Radius daerah berpenduduk jarang harus dipilih sedemikian hingga seseorang yang berada pada batas luar daerah ini tidak menerima dosis gamma total lebih dari 25 rem untuk seluruh tubuh atau dosis radiasi beta dari iodin lebih dari 300 rem untuk kelenjar gondok karena paparan awan radioaktif selama waktu paparan tak berhingga sebagai akibat dari terjadinya kecelakaan terparah secara keseluruhan. Jarak dari reaktor sampai pusat penduduk yang terdekat tidak boleh kurang dari $1 \frac{1}{3}$ kali radius daerah berpenduduk jarang. Yang dimaksud dengan pusat penduduk ini adalah daerah perkotaan yang berpenduduk lebih dari 25.000 orang.

\section{ANALISIS KEJADIAN AWAL YANG DIPOSTULASIKAN}

Analisis kejadian awal adalah menentukan hasil analisis keselamatan reaktor Kartini. Ada delapan analisis kejadian awal yang disyaratkan seperti kehilangan catu daya listrik, penyisipan reaktivitas batang kendali, kehilangan aliran pendingin primer, kehilangan air pendingin primer, kegagalan penanganan dan peralatan, bencana internal dan eksternal reaktor serta kesalahan manusia. Dari delapan analisis kejadian awal tersebut maka tujuh kejadian awal tidak akan menyebabkan paparan radiasi dan lepasnya zat radioaktif ke lingkungan. Sedang satu kejadian awal yang lainnya diperkirakan dapat mengakibatkan paparan radiasi dan lepasnya zat radioaktif ke lingkungan, sehingga perlu dilakukan analisis. Satu kejadian awal tersebut adalah kegagalan alat pemindah bahan bakar (transfer cask) pada saat digunakan untuk pemindahan bahan bakar di atas teras reaktor sehingga transfer cask tersebut jatuh yang mengakibatkan pecahnya seluruh kelongsong bahan bakar di teras.

Kegagalan transfer cask diasumsikan terjadi pada saat digunakan untuk pemindahan bahan bakar di atas teras reaktor sehingga transfer cask tersebut jatuh yang mengakibatkan pecahnya seluruh kelongsong bahan bakar. Pada kondisi kecelakaan secara kasar bahan-bahan radioaktif dibagi dalam dua sifat, yaitu ; bahan-bahan radioaktif yang bersifat gas (volatile) akan terlepas dari pengungkung reaktor, sehingga dapat menyebabkan dosis internal (dosis iodin) karena terhisap dan mengendap dalam kelenjar gondok dan dosis eksternal (paparan radiasi Gamma). Bahan-bahan radioaktif yang bersifat padat sedikit terikut bersama-sama dengan gas terlepas dari pengungkung reaktor ke atmosfir, sehingga hanya menyebabkan dosis eksternal.

Seluruh kelongsong elemen bahan bakar dalam teras mengalami pecah, karena kejatuhan transfer cask kemudian kehilangan seluruh air pendingin. Seluruh hasil fisi yang berupa gas terlepas dari matriks bahan bakar ke celah antara bahan bakar dan kelongsong. Kandungan bahan-bahan radioaktif dalam reaktor tergantung pada persen hasil belah, tingkat daya dan lamanya reaktor beroperasi. Dalam analisis diasumsikan reaktor beroperasi pada daya $100 \mathrm{~kW}$ dalam waktu yang cukup lama sehingga kandungan bahan-bahan radioaktif dalam teras telah mencapai kondisi setimbang, yaitu laju pembentukan inti hasil belah sama dengan laju peluruhannya.

Kecelakaan tersebut mengakibatkan pelepasan bahan-bahan radioaktif dari teras ke ruangan reaktor dengan asumsi : seluruh gas-gas mulia terlepas, $50 \%$ gas-gas halogen terlepas dan $1 \%$ dari hasil-hasil belah yang bersifat padat terlepas. Lima puluh persen dari iodin yang terlepas ke dalam ruangan reaktor akan lepas ke udara atau kelingkungan. Sisanya dianggap tertinggal atau akan melekat pada alat-alat dan permukaan bendabenda di dalam ruangan reaktor, karena sifatnya yang mudah bereaksi dengan zat di sekitarnya.

Dalam perhitungan dosis radiasi yang diterima penduduk, hasil-hasil belah yang bersifat gas yaitu Xe dan $\mathrm{Kr}$, dan isotop-isotop iodin harus diperhatikan karena isotop-isotop tersebut mudah menguap dan waktu paronya cukup panjang.

Seluruh bahan-bahan radioaktif yang berada dalam ruangan reaktor baik yang bersifat padat maupun gas merupakan sumber paparan radiasi eksternal.

Pelepasan bahan-bahan radioaktif dari ruangan reaktor ke atmosfir berlangsung dengan kecepatan tetap yaitu $0,1 \%$ per hari. Pelepasan dianggap melalui permukaan ruangan reaktor (leakage of seal), bukan melalui 
sistem filter karena blower harus dimatikan. Penyebaran bahan-bahan radioaktif dianggap terbawa oleh angin dengan tingkat turbulensi yang paling stabil.

\section{ANALISIS SEBARAN RADIOAKTIF}

Dalam analisis akan dibagi menjadi dua yaitu untuk radioaktif iodin (internal) dan gamma (eksternal). Asumsi yang diambil dalam analisis perhitungan dosis radioaktif yang dilepaskan ke lingkungan adalah jenis radioaktif dibagi dalam tiga bagian yaitu radioaktif jenis $\mathrm{A}$ yang terbentuk langsung melalui pembelahan seperti $\mathrm{I}^{135}, \mathrm{~K}^{87}, \mathrm{~K}^{88}$, radioaktif jenis $\mathrm{B}$ yang terbentuk langsung dari hasil pembelahan ditambah dengan sumbangan dari peluruhan induknya seperti $\mathrm{I}^{131}, \mathrm{I}^{132}, \mathrm{I}^{133}, \mathrm{I}^{134}, \mathrm{Xe}^{133}$ dan $\mathrm{X} \mathrm{e}^{135}$ dan radioaktif jenis $\mathrm{B}$ meta stabil yang karena induknya dapat meluruh melalui 2 (dua) cara, maka hanya fraksi (f) yang meluruh menjadi bahan radioaktif metastabil. Fraksi (1-f) meluruh menjadi isotop anak luruh yang lain seperti $\mathrm{Kr}^{85 \mathrm{~m}}, \mathrm{Xe}^{131 \mathrm{~m}}, \mathrm{Xe}^{133 \mathrm{~m}}, \mathrm{Xe}^{135 \mathrm{~m}}$.

Dosis internal yang diperhitungkan dalam analisis keselamatan ini adalah dosis yang berasal dari isotop iodin yang terlepas dari pengungkung reaktor (sebagai sumber radiasi beta). Untuk itu aktivitas jenuh iodin dan induknya harus dihitung lebih dulu, sebelum terjadi kecelakaan. Besarnya aktivitas jenuh untuk iodin jenis $A\left(R_{A}\right)$ dan untuk iodin jenis $B\left(R_{B}+R_{A}\right)$. Selanjutnya dihitung iodin yang terlepas dari reaktor dan dapat mencapai titik sejauh d meter dari reaktor tanpa pengenceran pada waktu t sesudah reaktor shutdown yaitu $N^{c}(t)$ atom. Laju dosis iodin yang diterima oleh kelenjar gondok adalah : ${ }^{[2,3,4,5,6]}$

$$
D^{\prime}=\frac{1,6 \cdot 10^{-8} \cdot f_{a} \cdot \bar{E}}{m} \cdot Q(t) \mathrm{rem} / \mathrm{detik}
$$

dengan

$$
\begin{array}{lll}
1,6.10^{-6} & =\text { faktor konversi energi, dalam erg/MeV } \\
f_{a} & =\text { fraksi iodin yang mengendap dalam kelenjar gondok } \\
\bar{E} & =\text { energi radiasi rata-rata yang terisap dalam kelenjar gondok tiap disintegrasi }
\end{array}
$$

Dosis total sampai t sesudah reaktor shutdown adalah :

$$
D_{T}=\frac{1,6 \cdot 10^{-8} \cdot f_{a} \cdot \bar{E}}{m} \lambda_{e} \cdot R \cdot S \cdot \int_{\frac{d}{u}}^{T} N^{c}(t) d t \mathrm{rem}
$$

dengan

$d=$ jarak dari sumber radiasi (teras) atau titik pelepasan iodin ke titik peninjauan (meter).

$U=$ kecepatan angin ( $\mathrm{m} /$ detik).

Dengan demikian dosis total sampai $t$ detik setelah reaktor shutdown adalah :

$$
D_{T}=\frac{1,6 \cdot 10^{-8} \cdot f_{a} \cdot \bar{E}}{m} \lambda_{e} \cdot R \cdot S \cdot(F P) A \cdot(F b) A \cdot \frac{R A}{\lambda_{A}} \cdot\left[\frac{e^{-\lambda_{A} \cdot \frac{d}{u}}-e^{-\lambda_{A} T}}{\lambda_{A}}-e^{\lambda_{1} \cdot \frac{d}{u}} \cdot \frac{e^{-\left(\lambda_{A}+\lambda_{1}\right) \frac{d}{u}}-e^{-\left(\lambda_{A}+\lambda_{1}\right) T}}{\lambda_{A}+\lambda_{1}}\right] \mathrm{rem}
$$
ialah : $[7,8,9]$

Laju dosis eksternal di udara pada jarak $d$ meter dari sumber dengan dianggap sebagai sumber titik

$$
D_{\gamma}^{\prime}=\frac{9,847 \cdot 10^{-13} \cdot E_{\gamma} \cdot \mu_{a} \cdot B_{u} \cdot e^{-\mu d}}{d^{2}} \cdot Q^{C}(t) \mathrm{rem} / \mathrm{detik}
$$

di mana :
$Q^{C}(t)$
$=\quad$ aktivitas dari isotop yang meman-carkan gamma. Lihat [Appendix $\mathrm{C}$ ]
$1,293.10^{3}$
$=$ berat udara per meter ${ }^{3}$ (gram $/$ meter $^{3}$ )
$B_{u} \quad=\quad$ build up factor yaitu perbandingan intensitas radiasi gamma pada suatu titik di
E $\quad=$ energi total gamma yang dipancarkan tiap disintegrasi (MeV/dis)
$\mu \quad=$ Koefisien absorpsi linear $\left(\right.$ meter $\left.^{-1}\right)$
на $\quad=$ Koefisien absorpsi tenaga $\left(\right.$ meter $\left.^{-1}\right)$ 
Dosis eksternal total :

$$
D_{\imath}=\frac{9,847 \cdot 10^{-13} \cdot E_{\gamma} \cdot \mu_{a} \cdot B_{u} \cdot e^{-\mu d}}{d^{2}} \cdot \int_{0}^{\tau} Q^{C}(t) \mathrm{dt} \text { rem }
$$

di mana :

$\tau=$ lama waktu penerimaan dosis eksternal (detik).

Dengan menggunakan persamaan di atas, dosis eksternal total dihitung, untuk isotop-isotop jenis $A$ dan jenis $B$ dan isotop metastabil adalah :

$$
D_{\tau}=\frac{9,847 \cdot 10^{-13} \cdot E_{\gamma} \cdot \mu_{a} \cdot B_{u} \cdot e^{-\mu d}}{d^{2}}\left[\left(F_{P}\right)_{B} \cdot\left(R_{B}+R_{A}\right) \frac{\left(1-e^{-\lambda_{B} \tau}\right)}{\lambda_{B}}+\left(F_{P}\right)_{A} \cdot \frac{\lambda_{\mathrm{B}} \cdot R_{A}}{\lambda_{\mathrm{B}}-\lambda_{\mathrm{A}}}\left(\frac{1-e^{-\lambda_{A} \tau}}{\lambda_{A}}-\frac{1-e^{-\lambda_{B} \tau}}{\lambda_{B}}\right)\right] \text { rem }
$$

Dari persamaan (3) dan (6) dapat disusun paket program komputer dengan bahasa turbo pascal seperti diagram alir program adalah seperti pada Gambar 1 yang dapat di-run dalam komputer pribadi (PC) dan lama eksekusi 5 menit. Sedangkan hasil running perhitungan dapat ditabelkan pada Tabel 1 dan Gambar 2 untuk dosis internal (iodin) dan Tabel 2 Gambar 3 untuk dosis gamma. Adapun parameter-parameter input yang digunakan dalam perhitungan untuk menentukan dosis lodin dan gamma total (external) setelah 2 jam pertama sesudah reaktor shutdown adalah sebagai berikut :

Sumber radiasi gamma maupun iodin akan meluruh dengan tetapan peluruhan $\lambda_{r}=7,0510^{-5}$ detik $^{-1}$, dengan peluruhan sebagai fungsi $t^{-0,21}$, di mana $t$ waktu sesudah reaktor shutdown dalam satuan detik.

Besaran-besaran dari bahan-bahan radioaktif campuran yang bersifat padat adalah sebagai berikut; $F_{p}=$ $0,01, \mu=1,0 \cdot 10^{-2}$ meter $^{-1}, \mu_{a}=3,8 \cdot 10^{-3}$ meter $^{-1}, k=\frac{\mu-\mu_{a}}{\mu_{a}}=1,6$ dan $B_{u}=1+k \mu d=1+1,6 \cdot 10^{-2} \cdot d .^{[10,11,12]}$

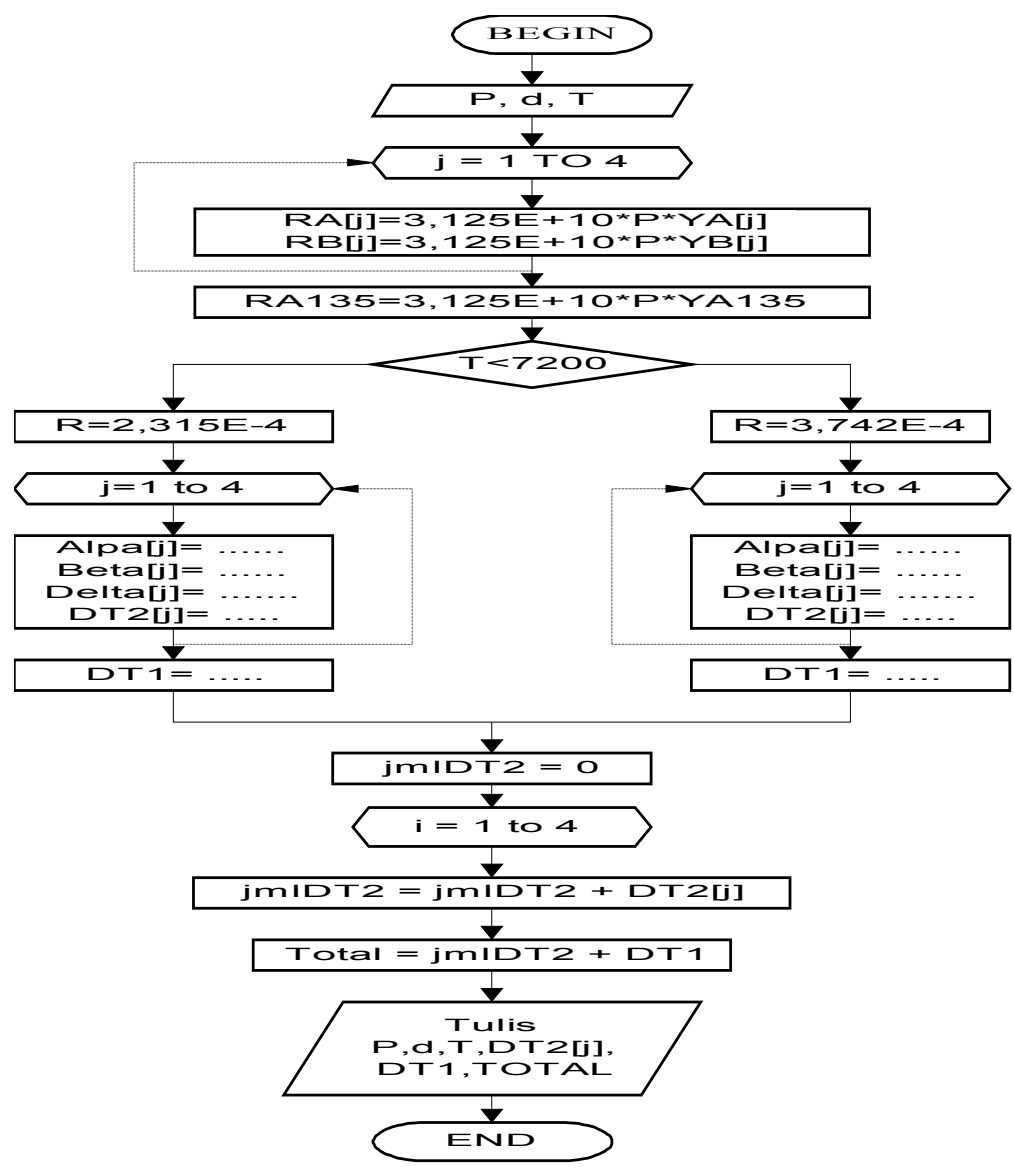

Gambar 1a. Diagram alir program perhitungan dosis iodin. 


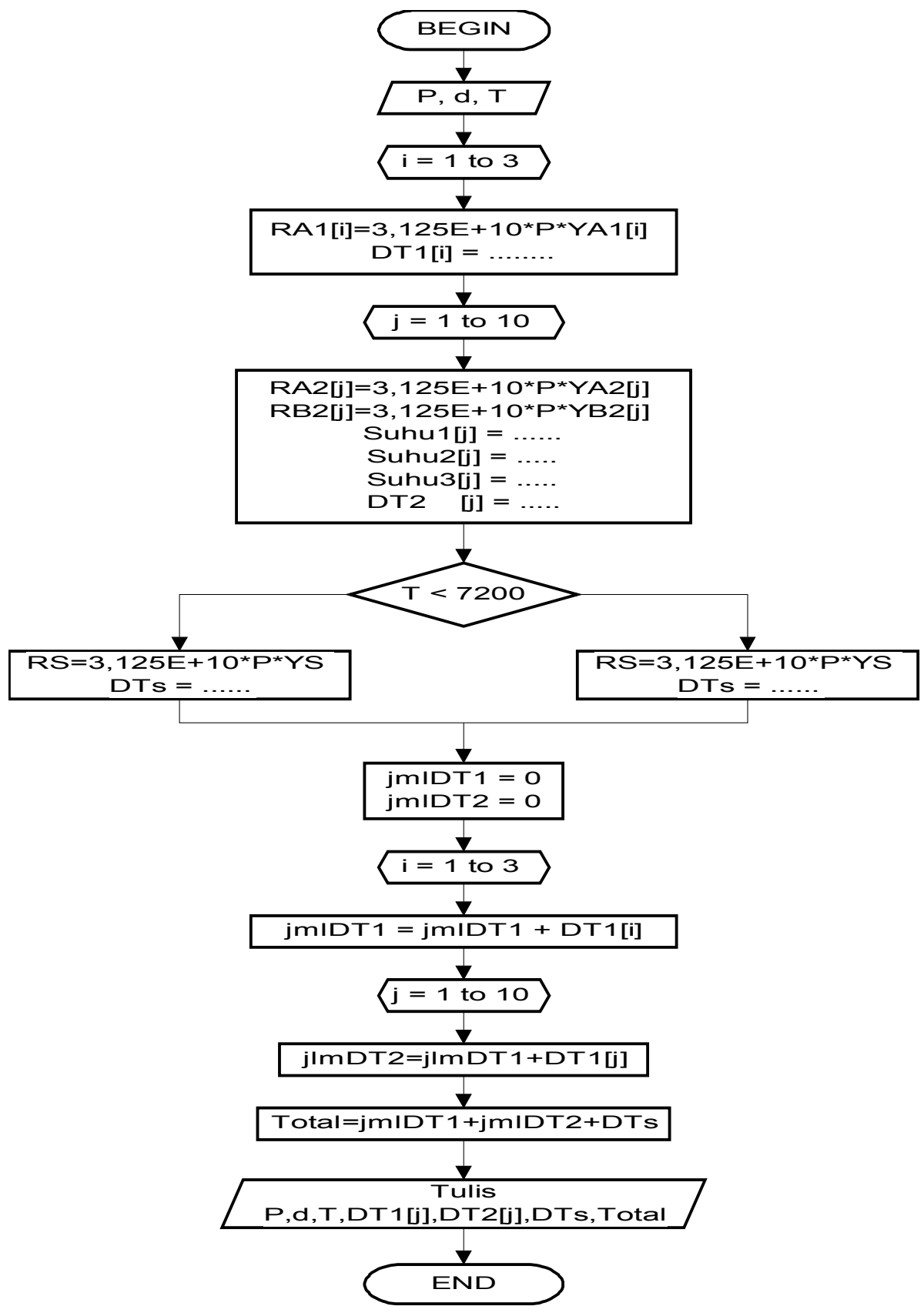

Gambar 1b. Diagram alir dosis gamma.

\section{HASIL DAN PEMBAHASAN}

Dari asumsi yang diambil dalam perhitungan dan postulasi kejadian awal maka sangat mempengaruhi hasil perhitungan baik dosis internal dan eksternal. Pertama adalah asumsi tentang reaktor Kartini $100 \mathrm{~kW}$ yang sudah dioperasikan pada waktu yang tak berhingga sehingga laju pembentukan hasil belah dalam bahan bakar sama dengan laju peluruhannya. Hal ini akan menghasilkan nilai yang sangat ekstrim dalam analisa keselamatan karena kenyataan- nya reaktor Kartini dioperasikan 100 kW dalam waktu 6 jam setiap hari dan 4 hari dalam 1 minggu dan bahkan rata-rata hanya dioperasikan 8 jam per hari dan 1 hari dalam 1 minggu. Jadi hal ini tidaklah menggambarkan suatu kejadian yang normal rata-rata dari kejadian dan pola operasi reaktor yang sesungguhnya. 
Kedua adalah dengan postulasi awal kejadian yang diambil yaitu jika transfer cask gagal (failure) maka akan menyebabkan seluruh kelongsong bahan bakar rusak/pecah (rupture) adalah kejadian yang sangat ekstrim yang mengakibatkan hasil perhitungan lepasan inti hasil belah pada Tabel 1 dan Tabel 2 serta Gambar 2 dan Gambar 3 ke lingkungan tidak menggambarkan kejadian yang normal. Tetapi menganut falsafah analisis keselamatan reaktor nuklir selalu diasumsikan dengan kejadian yang paling parah yaitu jika asumsi yang paling parah pun tidak berdampak yang fatal apalagi dengan kejadian kecelakaan yang biasa maka tidak akan berdampak fatal juga yang berarti aman.

Tabel 1. Hasil perhitungan dosis radiasi internal (iodin) pada saat 2 jam setelah terjadi kecelakaan.

\begin{tabular}{|c|c|c|c|c|c|c|}
\hline Jarak & \multicolumn{7}{|c|}{ Dosis radiasi beta (rem) } \\
\hline (meter) & $\mathrm{I}-131$ & $\mathrm{I}-132$ & $\mathrm{I}-133$ & $\mathrm{I}-134$ & $\mathrm{I}-135$ & TOTAL \\
\hline 5 & 29.650 & 28.790 & 723.540 & 15.730 & 0.3300 & 798.044 \\
\hline 10 & 20.850 & 20.790 & 510.680 & 10.590 & 0.1160 & 563.040 \\
\hline 15 & 16.990 & 17.094 & 416.560 & 8.490 & 0.0630 & 459.200 \\
\hline 20 & 14.700 & 14.850 & 360.470 & 7.280 & 0.0409 & 397.350 \\
\hline 25 & 13.140 & 13.310 & 322.180 & 6.475 & 0.0292 & 355.140 \\
\hline 30 & 11.990 & 12.160 & 293.920 & 5.880 & 0.0222 & 323.980 \\
\hline 35 & 11.100 & 11.270 & 271.940 & 5.430 & 0.0175 & 299.760 \\
\hline 40 & 10.380 & 10.550 & 254.220 & 5.062 & 0.0140 & 280.226 \\
\hline 50 & 9.280 & 9.440 & 227.100 & 4.500 & 0.0103 & 250.340 \\
\hline 60 & 8.470 & 8.620 & 207.070 & 4.095 & 0.0078 & 228.260 \\
\hline 70 & 7.842 & 7.981 & 191.480 & 3.777 & 0.0062 & 211.090 \\
\hline 80 & 7.334 & 7.465 & 178.900 & 3.521 & 0.0050 & 197.230 \\
\hline 90 & 6.914 & 7.038 & 168.470 & 3.310 & 0.0042 & 185.740 \\
\hline 100 & 6.558 & 6.675 & 159.640 & 3.130 & 0.0036 & 176.011 \\
\hline 125 & 5.865 & 5.967 & 142.370 & 2.780 & 0.0025 & 156.990 \\
\hline 150 & 5.353 & 5.442 & 129.594 & 2.520 & 0.0019 & 142.910 \\
\hline 175 & 4.955 & 5.034 & 119.630 & 2.320 & 0.0015 & 131.540 \\
\hline 200 & 4.634 & 4.705 & 111.580 & 2.154 & 0.0012 & 123.081 \\
\hline
\end{tabular}

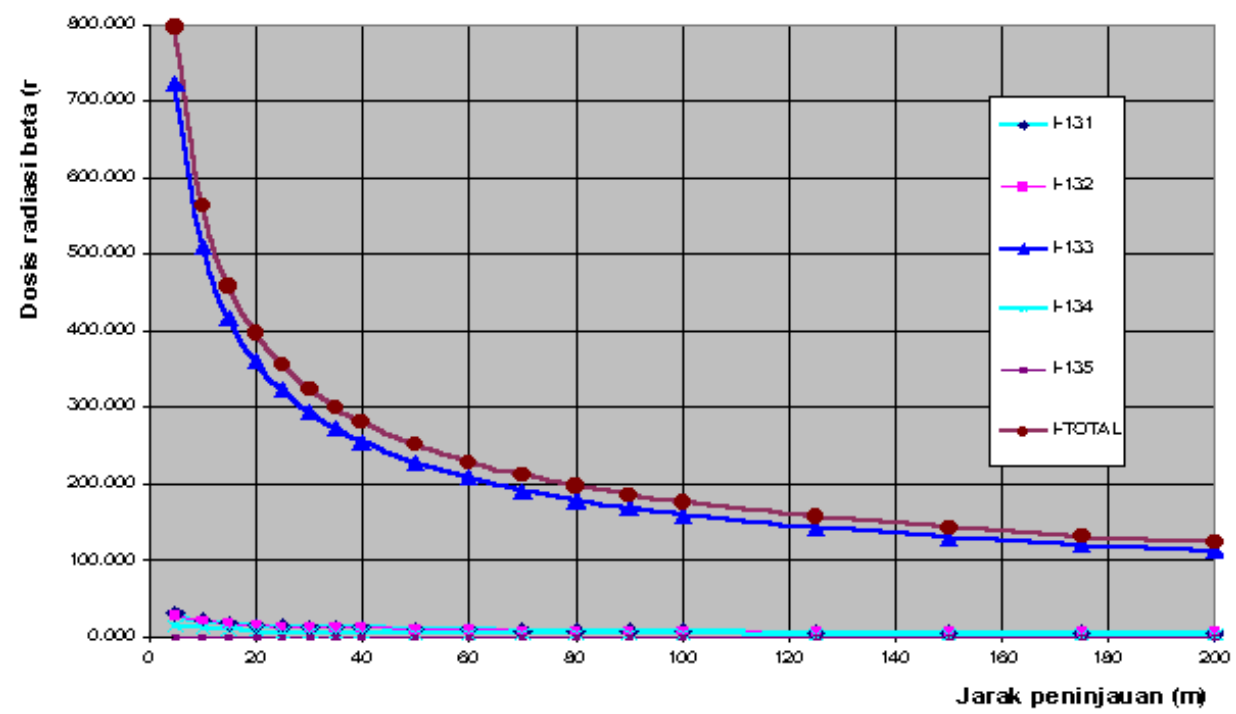

Gambar 2. Grafik dosis radiasi beta akibat kecelakaan pecahnya seluruh kelongsong elemen bahan bakar reaktor Kartini. 
Kejadian yang ekstrim juga diasumsikan pada saat kegagalan transfer cask terjadi, seluruh inti hasil belah gas lepas dari sistem matrik bahan bakar dan berada dalam celah bahan bakar. Kenyataannya bahwa tidak seluruh inti hasil belah gas lepas dari sistem matrik bahan bakar akan tetapi ikatan senyawa matrik bahan bakar masih mampu mengikat inti-inti hasil belah gas tersebut. Demikian juga dengan asumsi bahwa $50 \%$ dari total inti gas hasil belah dalam celah bahan bakar akan lolos ke lingkungan lewat filter particulate (absolut filter) dan ke cerobong setinggi 30 meter baru dilepaskan ke lingkungan.

Dengan asumsi tingkat kebocoran $1 \%$ dari total inti hasil belah gas yang lepas ke lingkungan melalui kebocoran seal (leakage seal) adalah kurang menggambarkan keadaan sesungguhnya karena kondisi gedung reaktor Kartini tidak kedap $100 \%$ dengan udara luar dan jika pada saat kecelakaan terjadi sistem ventilasi harus mati maka dengan mudahnya inti hasil belah gas lepas ke lingkungan melalui 3 pintu utama gedung reaktor pada lantai I, II dan III.

Dari berbagai asumsi dan kejadian awal yang dipostulasikan dalam analisis keselamatan reaktor Kartini $100 \mathrm{~kW}$ maka hasil perhitungan dosis radiasi gamma internal (iodin) dan gamma eksternal masih terdapat faktor kesalahan baik yang berasal dari sistem perhitungannya (paket program) maupun dari besaran-besaran yang diambil dalam perhitungan tersebut. Akan tetapi dengan adanya analisis perhitungan ini akan dapat digunakan dalam menentukan sebaran radiasi gamma sebagai fungsi jarak dari teras reaktor setelah 2 jam terjadi kecelakaan. Hasil perhitungan tersebut akan digunakan untuk menentukan jari-jari eksklusi reaktor Kartini dan keperluan tindak lanjut dalam program kedaruratan nuklir yang wajib harus dilakukan oleh pemegang ijin operasi reaktor yang dalam hal ini adalah pengusaha instalasi nuklir seperti yang tercantum dalam Surat Keputusan Kepala BAPETEN No.:01-P/Ka. BAPETEN/VI-1999. Adapun keputusan tersebut mensyaratkan bahwa dosis maksimum (dosis kecelakaan/darurat) yang boleh diterima petugas radiasi pada kondisi kecelakaan terparah adalah 25 rem untuk dosis ekstenal dan 300 rem untuk dosis iodin.

Tabel 2. Hasil perhitungan dosis gamma (eksternal) pada saat 2 jam setelah kecelakaan.

\begin{tabular}{|c|c|c|c|c|c|c|c|c|c|c|c|c|c|c|c|}
\hline \multirow{2}{*}{$\begin{array}{l}\text { Jarak } \\
(\mathrm{m})\end{array}$} & \multicolumn{15}{|c|}{ Dosis radiasi gamma (rem) } \\
\hline & $1 \cdot 135$ & Kr -87 & Kr -88 & |-131 & $1 \cdot 132$ & $1 \cdot 133$ & 1.134 & $x_{\mathrm{e}}-131 \mathrm{~m}$ & $\mathrm{xe}_{\mathrm{e}}-133 \mathrm{~m}$ & $x e-133$ & $\begin{array}{c}\text { Ye. } \\
135 \mathrm{~m}\end{array}$ & $\begin{array}{l}\text { Ye. } \\
135\end{array}$ & $\mathrm{Kr}-85$ & FPS & Gamma Total \\
\hline 5 & 108.18 & 12.97 & 140.12 & 25.16 & 93.37 & 113.662 & 212.92 & 0.294 & 2.827 & 43.28 & 25.36 & 91.16 & 12.21 & 1.196 & 882.709 \\
\hline 10 & 27.026 & 3.234 & 34.92 & 6.63 & 23.72 & 29.27 & 53.334 & 0.0852 & 0.781 & 13.96 & 6.55 & 25.2 & 3.446 & 0.306 & 228.4622 \\
\hline 15 & 11.98 & 1.432 & 15.46 & 3.07 & 10.67 & 13.31 & 23.72 & 0.042 & 0.374 & 7.26 & 2.98 & 12.064 & 1.67 & 0.1384 & 104.1804 \\
\hline 20 & 6.726 & 0.802 & 8.662 & 1.782 & 6.06 & 7.622 & 13.33 & 0.0254 & 0.222 & 4.513 & 1.711 & 7.169 & 1 & 0.0789 & 59.7033 \\
\hline 25 & 4.29 & 0.51 & 5.517 & 1.167 & 3.903 & 4.941 & 8.515 & 0.0171 & 0.148 & 3.0785 & 1.11 & 4.775 & 0.67 & 0.051 & 38.6926 \\
\hline 30 & 2.965 & 0.353 & 3.81 & 0.824 & 2.72 & 3.46 & 5.89 & 0.0123 & 0.106 & 2.22 & 0.779 & 3.41 & 0.49 & 0.0356 & 27.0740 \\
\hline 35 & 2.167 & 0.257 & 2.783 & 0.613 & 2 & 2.555 & 4.313 & 0.00925 & 0.0792 & 1.662 & 0.575 & 2.552 & 0.36 & 0.0262 & 19.95165 \\
\hline 40 & 1.65 & 0.196 & 2.116 & 0.472 & 1.531 & 1.96 & 3.286 & 0.00717 & 0.0612 & 1.278 & 0.4414 & 1.974 & 0.278 & 0.0201 & 15.27087 \\
\hline 50 & 1.0405 & 0.123 & 1.335 & 0.302 & 0.972 & 1.248 & 2.076 & 0.00458 & 0.0392 & 0.798 & 0.281 & 1.266 & 0.178 & 0.0128 & 9.67608 \\
\hline 80 & 0.71 & 0.0845 & 0.9123 & 0.207 & 0.666 & 0.854 & 1.42 & 0.0031 & 0.02677 & 0.523 & 0.192 & 0.863 & 0.121 & 0.0088 & 6.59144 \\
\hline 70 & 0.512 & 0.061 & 0.658 & 0.1484 & 0.48 & 0.613 & 1.022 & 0.00218 & 0.018 & 0.355 & 0.138 & 0.813 & 0.0856 & 0.0063 & 4.71340 \\
\hline 80 & 0.3836 & 0.04577 & 0.494 & 0.11 & 0.358 & 0.455 & 0.766 & 0.00158 & 0.0139 & 0.247 & 0.107 & 0.448 & 0.0622 & 0.0047 & 3.49675 \\
\hline 90 & 0.296 & 0.0354 & 0.382 & 0.0834 & 0.275 & 0.3478 & 0.59 & 0.00116 & 0.0104 & 0.175 & 0.0783 & 0.335 & 0.0462 & 0.0036 & 2.65926 \\
\hline 100 & 0.234 & 0.028 & 0.303 & 0.0644 & 0.216 & 0.27 & 0.466 & 0.000872 & 0.0079 & 0.125 & 0.0608 & 0.255 & 0.0349 & 0.0028 & 2.068682 \\
\hline 125 & 0.138 & 0.0169 & 0.1824 & 0.0359 & 0.125 & 0.154 & 0.277 & 0.00044 & 0.00418 & 0.0571 & 0.0345 & 0.135 & 0.01815 & 0.0016 & 1.1812 \\
\hline 150 & 0.0895 & 0.0109 & 0.118 & 0.0211 & 0.078 & 0.0931 & 0.176 & 0.000238 & 0.00234 & 0.0272 & 0.0208 & 0.0755 & 0.00983 & 0.001 & 0.723598 \\
\hline 175 & 0.0603 & 0.0075 & 0.081 & 0.013 & 0.0506 & 0.0586 & 0.118 & 0.000132 & 0.00135 & 0.0134 & 0.01306 & 0.0437 & 0.00562 & 0.0006 & 0.466897 \\
\hline 200 & 0.04212 & 0.0053 & 0.057 & 0.00816 & 0.034 & 0.038 & 0.0818 & 0.000074 & 0.000804 & 0.00673 & 0.00844 & 0.026 & 0.00326 & 0.0004 & 0.312207 \\
\hline
\end{tabular}




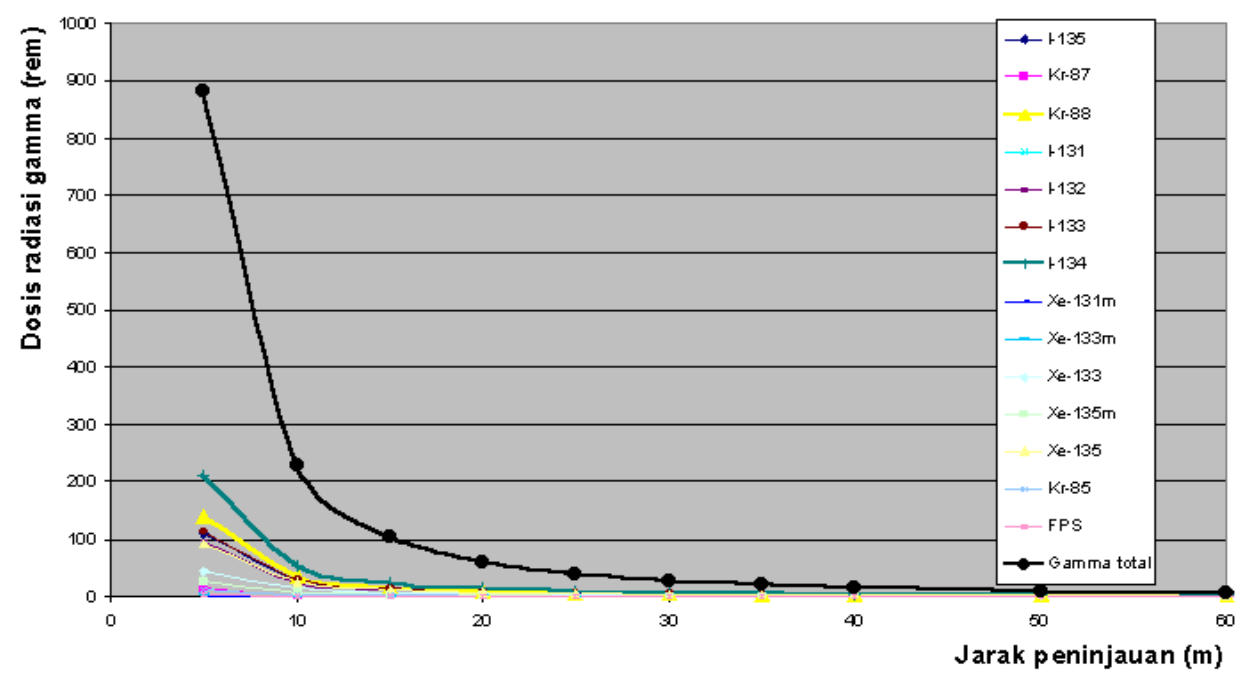

Gambar 3. Grafik dosis gamma akibat kecelakaan pecahnya seluruh kelongsong elemen bahan bakar reaktor Kartini setelah 2 jam.

Berdasarkan hasil perhitungan dari Tabel 1 dan 2 serta Gambar 2 dan Gambar 3 diperoleh bahwa jari-jari daerah eksklusi adalah 33 meter. Berdasarkan hasil analisis di atas maka untuk mengamankan daerah eksklusi tersebut sangat mudah dilakukan karena masih berada di dalam kawasan BATAN Yogyakarta. Hal ini sesuai dengan syarat pembangunan letak reaktor, sehingga bahaya radiasi hanya terlokalisir dalam kawasan Reaktor Kartini (BATAN Yogyakarta).

\section{KESIMPULAN}

Dengan asumsi bahwa dari delapan postulasi kejadian awal yang ada di reaktor Kartini maka hanya satu postulasi kejadian awal yang akan berpotensi terlepasnya inti hasil belah dari sistem bahan bakar maka dapat disimpulkan bahwa dosis radiasi gamma internal (iodin) 300 rem dan dosis radiasi gamma 25 rem pada jarak 33 meter dari teras reaktor pada saat 2 jam setelah terjadi kecelakaan. Berarti proses evakuasi yang dilakukan pada program kedaruratan nuklir tidak perlu melibatkan penduduk sekitar kawasan Batan Yogyakarta.

\section{DAFTAR PUSTAKA}

1. Postulated Initiating Event of Kartini Research Reactor, Research and Develop Centre for Advanced Technology, Dokumen No. : INS/02/BR-IE/07/2003.

2. EL-WAKIL, M. M., Nuclear Heat Transport, The American Nuclear Society, Illinois, 1978.

3. HETRICK, D. L., Dynamics of Nuclear Reactors, The University of Chicago Press, Chicago, 1971.

4. KREYZIG, E., Advanced Engineering Methematics, John Wiley and Sons Inc., New York, 1983.

5. LEWIS.E.E., Nuclear Power Reactor Safety, John Wiley and Sons Inc, New York, 1977.

6. LAMARSH, J.R., Introduction to Nuclear Reactor Theory, Addison-Wesley Publishing Company Inc. Massachusetts USA, 1966.

7. LAMARSH, J.R., Introduction to Nuclear Engineering, Addison-Wesley Publishing Company Inc. Massachusetts USA, 1983.

8. THOMSON,T.J., BECKERLEY, J.G., The Technology of Nuclear Safety, vol 2, Reactor Material and Engineering, The M.I.T. Press, 1973.

9. VERNURI,V. and KARPLUS, W.J, Digital Computer Treatment of Partial Differential Equations, Prentice Hall Inc., Englewood Cliffs, New Jersey, 1981.

10. WEISMAN, J., Element of Nuclear Reactor Design, Elsevier Scientific Publishing Company, Amsterdam, 1977.

11. EL-WAKIL M.M., Nuclear Heat Transport, International Textbook Company, Scranton, Pensylvania, 1971.

12. DUDERSTADT J.J. and HAMILTON J.H., Nuclear Reactor Analysis, John Wiley \& Sons Inc., New York 1976. 